\title{
La incorporación de la cultura digital en las prácticas de lectura de los estudiantes de bachillerato de la UNAM
}

\author{
Elsa Margarita Ramírez Leyva *
}

Artículo recibido:

8 de noviembre de 2011.

Artículo aceptado:

6 marzo de 2012.

\section{RESUMEN}

La cultura digital es considerada una innovadora cultura de lectura, la cual ha dado lugar a cambios en las modalidades de informarse e informar. Asimismo se ha configurado la identidad de "nativo digital" para caracterizar, en particular, a las jóvenes generaciones que coinciden con el nacimiento y desarrollo de la tecnología electrónica, y se les concibe como usuarios intensivos de los artefactos tecnológicos, asimismo con habilidades de lectura y escritura electrónica, y a la vez con una declinación progresiva por el interés de la lectura de medios impresos. En el presente artículo se presenta el resultado del análisis que tuvo el propósito de explorar las representaciones de la cultura digital

* Centro Universitario de Investigaciones Bibliotecológicas de la UNAM, México. eramirez@unam.mx

INVESTIGACIÓN BIBLIOTECOLÓGICA, Vol. 26, Núm. 56, enero/abril, 2012, México, ISSN: 0187-358X. pp. 43-69 
en el contexto de las actividades de lectura e informativas de un grupo de estudiantes de Bachillerato de la UNAM. Para tal fin se analizaron los fragmentos de las narraciones relativas al tema, recopiladas entre 2010 y 2011 para la investigación sobre representaciones y las prácticas de lectura e informativas de dicha comunidad. **

Palabras clave: cultura digital, nativos digitales, representaciones y prácticas de lectura.

\section{ABSTRACT}

Incorporation of Digital Culture in the UNAM High School Students' Reading Practices Elsa Margarita Ramírez Leyva

Digital culture is considered an innovative culture of reading, which has given rise to changes in patterns of getting informed and inform. The identity of "digital native" has been also configured to characterize, in particular, the young generations that coincide with the birth and development of electronic technology, and they are conceived as intensive users of technological artifacts, also with electronic writing and reading skills, and at the same time, with a progressive decline in their interest for printed media reading. This article presents the results of the analysis intended to explore representations of digital culture in the context of reading and informative activities of an UNAM high school students group. Fragments concerning the topic narratives, collected between 2010 and 2011 for research on representations and reading and informative practices of that community were analyzed for this purpose.

Keywords: Digital Culture, Digital Natives, Representations and Reading Practices. 
Sibien la cultura digital ofrece a los lectores un formato diferente, las prácticas de lectura no necesariamente están determinadas de manera absoluta por la tecnología.

Milad Doueinu

Para el estudiante, el hipertexto promete nuevos encuentros con el texto cada vez más centrados en el lector.

George P. Landow

\section{INTRODUCCIÓN}

T a cultura digital se considera una evolución de la literacidad, ${ }^{1}$ lectura y Lescritura, lo cual se manifiesta en las transformaciones de las textualidades electrónicas ${ }^{2}$ en las cuales interactúan diferentes códigos escritos, icónicos, sonoros y numéricos. En tanto la materialidad de los soportes y sus aplicaciones para la lectura y la escritura, al revolucionarse con la tecnología, ha producido diferentes posibilidades y prácticas de lectura escritura, producción, edición, preservación, organización, transferencia y uso de contenidos y también de comunicación por medio de diferentes tipos de artefactos. Por otro lado, el contexto sociocultural ha empezado a migrar, de manera palautina, a los ambientes tecnológicos en su modalidad virtual, dando lugar al denominado "ciberespacio", en donde las prácticas sociales relacionadas con la comunicación y el intercambio de información pueden realizarse en tiempo real o diacrónico. En suma, los artefactos, la configuración de los textos compuestos de diferentes lenguajes, las aplicaciones que facilitan la edición y la interactividad en el ambiente digital, les ofrecen a los lectores nuevas posibilidades y modalidades de lectura y de escritura, de usos, de producción de contenidos, de acceso. Todo ello en el contexto actual en donde coinciden el modelo de cultural digital, el proyecto de sociedad de la información y el conocimiento así como las TIC, que en su conjunto establecen valores y normas en las relaciones de los sujetos con la palabra escrita, no sin consecuencias, toda vez que transfiguran las identidades de los lectores, las representaciones, las prácticas y los usos sociales de la lectura y la escritura.

1 Concepto adoptado por investigadores de Hispanoamérica. Abarca conocimientos y actitudes que asume una comunidad en el manejo del código escrito. Asimismo se ha incluido en los enfoques socioculturales sobre el estudio de las prácticas sociales de lectura.

2 Esta noción se ha incluido en la terminología de los filólogos para designar a la literatura digital, la cual refiere a las nuevas formas textuales que solamente cobran vida en el marco del ordenador. Cfr. Laura Borras Castanyer. (2002) Teorías literarias y retos digitales, en Textualidades electrónicas. Nuevos escenarios para la literatura, España: UOC. p. 49. 
En efecto ahora las generaciones de niños y jóvenes, desde edades cada vez más tempranas, al hacer uso de los medios electrónicos, — por ejemplo consolas para videojuego, tabletas, computadoras o teléfonos móviles- miran, escuchan, leen, escriben juegan, aprenden, se informan. Asimismo ingresan al ciberespacio en donde se comunican y construyen redes sociales a través de las cuales establecen amistades o grupos, no sólo de su ámbito local sino también de distintas partes del mundo. Es importante destacar que al mismo tiempo esas jóvenes generaciones todavía leen una buena cantidad de publicaciones en papel, escriben a mano, asisten a las bibliotecas y en sus hogares tienen libros que leen sentados, recostados, de pie, en la cama, en el baño, al aire libre, en el transporte, en silencio, en susurro o en voz alta y solos o acompañados. Tanto en el medio electrónico como en el impreso se lee por obligación o por gusto y de manera superficial o profunda para estudiar, entretenerse o informarse.

Sin duda la bibliotecología ha avanzado al incorporar la cultura digital en sus teorías y métodos dirigidos al estudio y desarrollo de modelos de bibliotecas digitales, de desarrollo de colecciones y de organización documental, entre otros aspectos relativos al universo de los materiales. También se han innovado los modelos de formación de usuarios y de lectores, con el fin de contribuir al perfeccionamiento de sus habilidades que les permitan identificar, seleccionar, usar y aprovechar los diferentes tipos de contenidos y así fortalecer sus facultades, resolver problemas y realizar de la mejor manera las actividades que emprendan. Y para que a la vez ejerzan el derecho a informarse y a informar de manera responsable. No obstante, ante las constantes transformaciones sociales, culturales y tecnológicas que están innovando de manera permanente los medios y las formas sociales de informar e informarse, se hace necesario revisar las teorías, los paradigmas y las prácticas bibliotecológicas con la finalidad de renovar el lazo social de la institución bibliotecaria con sus comunidades. Además también hay que actualizar la formación de los bibliotecólogos desde una perspectiva transdisciplinaria por medio de la cual se articulen a la bibliotecología saberes humanísticos, sociales, legales y tecnológicos, en tanto que las sociedades se tornan más complejas en la medida en que progresa el modelo global, y a su vez la información se fortalece como recurso estratégico para el desarrollo y la transición a la denominada sociedad del conocimiento para la cual se requiere una mayor intervención bibliotecaria para un mejor desarrollo de comunidades lectoras e informadas.

En este artículo relacionamos dos aspectos relativos a la lectura en la sociedad actual: uno aborda el progreso de la cultura digital en el ámbito de la escritura y la lectura, y el otro los cambios en las nuevas generaciones, en especial las de los jóvenes estudiantes, quienes constituyen una comunidad 
heterogénea que no corresponde de manera cabal a la identidad de "nativo digital" que es como se tiende a caracterizar a las generaciones que han nacido en el contexto de la cultura digital. En algunos ámbitos incluso se promueve ese tipo de identidad, mientras que en otros preocupa que los jóvenes lleguen a convertirse en ese tipo de nativos y abandonen los medios impresos y las formas placenteras de lectura que proponía el libro tradicional. Sin embargo en esta investigación sobre "Las representaciones y prácticas de lectura de los estudiantes del Bachillerato de la UNAM", identificamos algunos fragmentos de las narraciones recopiladas entre 2010 y 2011 entre los jóvenes entrevistados que cursan el último año de la licenciatura, algunas opiniones y los usos que ellos hacen de los medios digitales. Incluimos en este artículo fragmentos de las entrevistas que consideramos más representativas, a fin de mostrar que a pesar de formar parte de una generación que ha crecido a la par de esa cultura que utiliza los artefactos electrónicos de manera cotidiana, no corresponden a cabalidad con la denominada identidad de "nativo digital", dado que en sus representaciones y prácticas no predomina la cultura digital; más bien se encuentran todavía anclados, de manera sólida, a los medios de la cultura impresa.

Desde la perspectiva con la que se mira la cultura digital en este artículo, consideramos innecesario entrar en el debate sobre el fin de la era de Gutenberg y hablar sobre la muerte del libro impreso y la extinción de la especie lectora, dado que la nueva cultura ofrece nuevas posibilidades de lectura y escritura que se suman a las establecidas por la cultura impresa. Seguramente los avances tecnológicos para crear un tipo de papel electrónico renovarán el formato del libro, que se asemejará en su forma al impreso, pero desde luego adicionado con innovadoras funciones. ${ }^{3} \mathrm{Al}$ respecto es oportuno recordar esta cita de Umberto Eco: "El libro es como la cuchara, la rueda, las tijeras. Una vez que se han inventado, no se puede hacer nada mejor". ${ }^{4}$ En este orden de ideas es importante destacar el papel que ha de jugar la bibliotecología para preservar y armonizar los recursos bibliográficos y documentales tanto en su forma impresa como electrónica, y también para desarrollar los servicios virtuales destinados a complementar y facilitar el acceso a la información registrada en diferentes medios.

3 Las investigadoras Jie Qi y Leah Buechley, especialistas en ingeniería del papel, del Instituto Tecnológico de Massachusetts, crearon un tipo de libro infantil denominado Electronic Popable, el cual se despliega y crea figuras en tercera dimensión, es de papel activado por microchips para generar sonidos y movimientos. Cfr. Jie Qi \& Lean Buechley, Electronic popables: exploring paper-based computing through an interactive pop-up book. <http://web.mit. edu/jieqi/Public/DREU_Site/Jie_Qi_DREU.pdf $>$ [consultada: 15/agosto/2011].

4 Jean-Claude Carrière y Umberto Eco (2010), Nadie acabará con los libros, México: Lumen, p. 20. 
La cultura digital, al igual que todas las culturas tiene sus códigos fundamentales, como los denomina Michel Foucault, y "son los que rigen su lenguaje, sus esquemas perceptivos, sus cambios, sus técnicas, sus valores, la jerarquía de sus prácticas fija de antemano para cada hombre los órdenes empíricos con los cuales tendrá algo que ver y dentro de los que se reconocerá". Coinciden con este enfoque las perspectivas sociológica y antropológica que consideran como cultura a las normas, creencias y actitudes que todo individuo aprende y comparte. Por tanto es importante conocer los medios y las técnicas con las cuales no sólo la gente actúa en su comunidad, sino que también son aquellos que la humanidad ha creado para sobrevivir y preservar su especie.

En relación con lo anterior, Adolfo Mir afirma que los componentes de toda cultura se agrupan en tres grandes categorías: 1) Las instituciones, conformadas de estructura, y funciones para regular y controlar las pautas normativas de todos los aspectos de la vida social, de tal manera que las acciones de los individuos obedezcan a patrones vigentes que aprenden y comparten con su comunidad. 2) Ideas, creencias y valores que constituyen teorías, conocimientos, observaciones, tradiciones o experiencias que los sujetos tienen sobre sí mismos y sobre su mundo biológico y social, y que de alguna manera guían sus acciones; en tanto que los valores son preceptos que determinan los juicios de valor (y que por lo general se presentan en binomios opuestos, bueno/malo, correcto/incorrecto, etc.). 3) El aspecto tecnológico, conformado por los objetos y las herramientas que el hombre crea y utiliza. Los usos sociales de los objetos culturales se relacionan con las actitudes, valores y creencias que se les asignan, y también se relacionan con los conocimientos y las habilidades que implican. ${ }^{6}$ Sin duda la bibliotecología está involucrada con estos tres componentes de la cultura, en donde la institución bibliotecaria como órgano normativo de la preservación y el uso de los materiales bibliográficos y documentales, promueve y a la vez se rige por las representaciones sociales, los valores, teorías y preceptos sobre los usos de los objetos o artefactos escritos y audiovisuales, y de igual manera participa respecto a la conformación de las prácticas sociales de lectura e informativas.

Esas condiciones señaladas por Mir se manifiestan en la cultura digital que empieza a influir en la sociedad actual, aun cuando la mayoría de los ciudadanos del mundo pertenecemos todavía a la cultura del texto impreso, que

5 Michel Foucault. (1991), Las palabras y las cosas. Una arqueología de las ciencias bumanas / trad. E.C. Frost, $21^{\text {a }}$ ed. México: Siglo XXI, p. 5. 
se remonta al origen de la escritura y que se conformó y consolidó gracias a la invención tipográfica. Al respecto Jesús Galindo afirma:

Incluso la cultura digital puede considerase como parte de un proceso evolutivo de las técnicas y artefactos desarrolladas por los seres humanos aplicados en el sistema social del lenguaje escrito, que data de varios siglos, tangibles en la transformación del soporte, la textualidad y las prácticas de escribir y leer. ${ }^{7}$

Esta evolución digital abre un entorno virtual constructivo inédito en donde es factible visualizar mundos posibles que los actores sociales crean y transforman en forma de redes abiertas; incluso se tejen vínculos sociales en torno a ese mundo simulado, en el cual las normas y los valores pueden modificarse al gusto de los internautas. ${ }^{8}$ En este sentido no es la tecnología por sí sola la que propicia los cambios culturales, como bien señala Christine Hine, la Internet es un espacio en el cual se gesta una cultura; y es importante destacar la observación de la autora en coincidencia con Grint y Woolgar, respecto de la formación de la cultura digital, ellos destacan que en todas las culturas -la digital no es la excepción- el agente de cambio no es la tecnología en sí misma, sino los usos y la construcción de sentido alrededor de ella. ${ }^{9}$ En esta misma línea de pensamiento, Rosalía Winocur afirma que la interacción cotidiana de las personas con los artefactos digitales ha creado un vínculo mutuamente constitutivo de nuevos nichos culturales de producción que tienen un significado cultural. Ya no sólo se usan como tecnologías de información y comunicación, sino que se comportan imaginariamente como artefactos rituales. Y la autora concuerda con Dan Adaszko en cuanto a que el imaginario tecnológico es

el entramado de imágenes e ideas que el hombre se hace acerca de la tecnología y su relación con ella; un conjunto de representaciones que conforma un determinado orden y [le] da sentido a la relación del hombre con el resto de la sociedad y con el universo que lo rodea. ${ }^{10}$

Desde esta perspectiva, Winocur señala

7 Jesús Galindo Cáceres (2006), Cibercultura, ciberciudad, cibersociedad. Hacia la construcción de mundos posibles en nuevas metáforas conceptuales, en Cibercultura. Un mundo emergente y una nueva mirada, México: Consejo Nacional para la Cultura y las Artes, pp. 48-49.

8 Ibídem.

9 Citada por Christine Hine (2004), Etnografía virtual, Barcelona: Editorial UOC, p. 13, (Nuevas Tecnologías y Sociedad).

10 Rosalía Winocur (2009), Robinson Crusoe y tiene celular, México: Siglo XXI, Universidad Autónoma Metropolitana, p. 19. 
que Internet y el celular no [son] la relación pragmática con un objeto sino con las relaciones culturales, con las cuales esa tecnología se articula en diversas condiciones socioculturales. ${ }^{11}$

De esta manera las relaciones construidas por la sociedad con los medios y formas electrónicas han propiciado que lo digital cobre el estatuto de cultura como parte de la comunicación escrita. En este sentido, Milad Doueihu reconoce que la cultura digital es una cultura de lectura, en donde la imagen y la palabra comparten un entorno nuevo, cohabitan en un campo emergente de producción de sentidos y de saber. Agrega que esta cultura es un proceso civilizador, un poderoso agente de cambio que tiene su propio lenguaje, el cual ha empezado a remodelar las lenguas oral y escrita, - - y añadiríamos, también al lenguaje icónico — tal proceso alude a una identidad digital y a un orden social. ${ }^{12}$ Doueihu define esta cultura como un conjunto de tecnologías que producen prácticas sociales, compuesta por modos de comunicación y de intercambio de informaciones que desplazan, redefinen y remodelan el saber en formas y formatos nuevos, y por métodos para adquirir y transmitir dicho saber. Por ello, propone que la cultura digital y su entorno fluctuante deben examinarse como un conjunto de prácticas discursivas que tiene sus propias normas y convenciones, las cuales tienden a perturbar y debilitar tanto las categorías como los valores establecidos. ${ }^{13}$

La cultura digital también es denominada cibercultura. Pierre Levy define este neologismo como

el conjunto de técnicas (materiales e intelectuales) de las prácticas, las actitudes, de los modos de pensamiento y de los valores que se desarrollan conjuntamente en el crecimiento del ciberespacio. ${ }^{14}$

En cuanto a este último término, Levy lo vincula a la estructura en red y lo considera "el nuevo medio de comunicación que emerge de la intercomunicación mundial de los ordenadores," 15 lo cual refiere no solamente a la infraestructura, también incluye el oceánico universo de las informaciones que contiene y a los seres humanos que navegan por él y lo alimentan. ${ }^{16}$

11 Ibid.

12 Milad Doueihu (2010), La gran conversión digital, Buenos Aires: Fondo de Cultura Económica, pp. 22-24, 211

13 Ibid., p. 35.

14 Levy Pierre (2007), Cibercultura. La cultura de la sociedad digital, México: Anthropos, Universidad Autónoma Metropolitana, Unidad Iztapalapa, p. 1.

15 Ibid.

16 Ibid. 
En el modelo cultural digital, como en el escenario de la sociedad de la información y la tecnología electrónica, coinciden factores que dan lugar a las condiciones en las que se reconfiguran identidades, cambios y regularidades, similitudes y diferencias en las relaciones entre lectores con las textualidades y los soportes. También de aquí se derivan los usos y las representaciones, las prácticas de lectura y escritura que han empezado a cobrar sentido y significado en la sociedad del texto del presente siglo. Y es precisamente en la interacción social, como señala Dominique Picard, donde pueden apreciarse

las regularidades, elementos repetitivos[;] reglas implícitas y explícitas, [y] se puede percibir la influencia de los valores, de normas, de conductas que tienden a estructurar y a orientar el comportamiento. ${ }^{17}$

Además, las similitudes reducen la multiplicidad aparente de comportamientos de los individuos, según su categoría social, género, edad y profesión, en cada grupo se reconocen modos de expresión, actitudes, usos y costumbres comunes. Y la estructura normativa determina el tiempo y el espacio, y orienta los comportamientos, actitudes y gestos que se ordenan de manera binaria en opuestos.

\section{LOS NUEVOS ARTEFACTOS CULTURALES}

Los artefactos electrónicos: computadora, videoconsolas, TV digital, teléfono móvil, tabletas, el ipod, constituyen objetos culturales en tanto que sus usos están determinados por valores y normas sociales sobre los contenidos, como sucede con los medios impresos, pero la novedad radica en las posibilidades de acceso e interacción con los contenidos y sus potencialidades, las cuales dan lugar a la construcción de relaciones simbólicas. A este respecto es pertinente la propuesta de Karen Littau orientada hacia el libro impreso, al cual concibe como constituido por dos partes: una de orden material y la otra del orden de las ideas. Estas dos condiciones corresponden también a los artefactos electrónicos, lo cual tiene efecto en la relación simbólica que los lectores establecen con ellos. Los medios se desdoblan en dos dimensiones o naturalezas, como señala Cathy N. Davidson, "no son lo mismo" porque uno de ellos es "artefacto manufacturado", y el otro un "transmisor de significado". ${ }^{18}$ El lector no sólo establece una determinada relación con el

17 Picard Dominique (1986), Del código al deseo. El cuerpo en la relación social, Argentina: Paidós, p. 25.

18 Citado por Karen Littau, Teorías de la lectura, Buenos Aires: Manantial, p. 18. 
contenido sino también con el objeto o soporte; es decir a través de su cuerpo físico. Sobre ello, Littau afirma que:

los textos son herramientas que transmiten significados complejos con múltiples estratos. Los textos ponen en contacto el contenido, la forma y la materia y los lectores reaccionan ante los códigos, lingüísticos literarios, además de hacerlo ante los bibliográficos del medio. ${ }^{19}$

Como ya lo anticipaba Don F. McKenzie: "Un texto, al ser también un objeto material, su materialidad y organización física condicionan nuestra lectura”. ${ }^{20}$ De alguna manera ordena la lectura, por ello el lector establece relaciones con la materialidad del soporte y con el contenido; por ejemplo entre los bibliófilos el objeto en sí mismo resulta más valorizado por el tipo y la calidad de su composición, surge la pregunta ¿con qué establecerá el lector la valorización en medios digitales, con el artefacto?

A diferencia del medio digital, es importante aclarar que el origen simbólico de los "libros de papel" se gesta en la categoría privilegiada de la autoridad de los contenidos, tales como la religiosa, civil o académica; si nos remitimos a los antiguos textos destacan los escritos sagrados, las leyes, el conocimiento. Cabe preguntar en qué figura o elemento se ancla la relación simbólica de los lectores con los contenidos y la materialidad de los artefactos electrónicos es decir, valores, creencias y normas, dado que ahora a los contenidos electrónicos les son agregadas cualidades multimedia. Podríamos afirmar que el atractivo del libro multimedia electrónico es el de constituirse en un espacio en donde el lector manipula los contenidos, los modifica a su gusto, y el artefacto lo mismo le sirve para leer y aprender, que para jugar, mirar, escuchar y comunicarse, lo cual tiene efectos en las representaciones, los usos y las prácticas de lectura y escritura. Sin embargo, para no pocos lectores el "libro de papel" es preferido precisamente por las características físicas que lo hacen tangible, además privilegia la posibilidad de la posesión, más que el acceso, como es el caso de la red, en donde lo importante es el acceso y la rapidez para obtener contenidos o comunicarse desde cualquier lugar.

Por lo que se refiere a los contenidos electrónicos, éstos no se han legitimado de manera homogénea. En algunos ámbitos científicos y académicos las revistas, que en su forma impresa gozan de un prestigio de muchos años, son preferidas en su formato electrónico, pero en otros ámbitos los libros y

19 Ibid.

20 Don F. McKenzie (2005), Bibliografía y sociología de los textos, trad. Fernando Bouza, España: Akal, p. 31 (Akal Universitaria, Historia moderna). 
las publicaciones electrónicas no tienen la misma aceptación que los impresos, excepto que haya migrado del impreso al formato electrónico. En cambio las publicaciones que nacen electrónicas son objeto de discusión respecto de la calidad de los contenidos. Por otro lado los contenidos que se difunden y son de libre acceso por Internet, dada la diversidad de autorías, son objeto de duda en cuanto a su calidad y veracidad, en especial cuando los lectores desconocen la variedad de recursos que sí están validados, por ejemplo, los que ofrecen las bibliotecas virtuales o instituciones de prestigio.

A este respecto entre los estudiantes entrevistados se identificaron las opiniones más frecuentes sobre la calidad y veracidad de la información que se encuentra en Internet, las cuales ilustramos con las siguientes declaraciones:

\section{Mauricio 18 años}

Sí, de hecho también me baso en los libros que me piden de biología o administración y de todas las materias que llevo saco libros, pero aun así trato de seguir buscando información de Internet para complementarla y comparar, porque de repente dicen que en Internet hay libros malos o incompletos.

\section{Axel 18 años}

Si se piensa mejor, no hay gran variedad en Internet; de pronto se piensa que sí, pero acabas "bajando" el libro, mejor lo busco en físico. Wikipedia te da una idea general del tema, igual para "bajar" bibliografía, pero de ahí en fuera no es una fuente de información confiable.

\section{Sandra 18 años}

Pero así como que le tengo más confianza a un libro, que lo que dice el Internet.

\section{Paloma 18 años}

A mí me gusta Wikipedia ahorita, yo siento que tiene como para darte una idea de lo que te están dejando los profesores o, de lo que estás buscando, pero no para basarte en ellos, porque muchas veces uno sabe unas cosas y dice "es que esto no es cierto", entonces cómo... entonces yo siento que es como la orientación, como el punto a partir de lo que uno va a hacer.

\section{LA LECTURA EN LA CULTURA DIGITAL}

Los cambios culturales tienden a modificar las significaciones. Por lo que respecta a la lectura hoy ésta se extiende más allá de las definiciones que la refieren a las habilidades para descifrar un código de signos escritos; es decir, como los únicos objetos pertinentes, ahora se incorporan las imágenes y la lectura se extiende a la comprensión del sentido de cualquier otro tipo de representación gráfica. A su vez toda transformación en la "textualidad", el soporte y el contexto social y cultural, tiene efectos en el acto y las prácticas 
de lectura y escritura, como lo han demostrado los estudios de la historia de la cultura escrita. Entendida la lectura como la puesta en actividad de las capacidades intelectuales, cerebrales y sensibles ante el texto materializado en algún soporte, ese acto participa en el desciframiento del código, en la comprensión de los contenidos y en la construcción de sentido y de significado, es decir, la producción que de todo ello se derive, como el conocimiento, la experiencia estética y la información.

En cuanto a las segundas, se refieren a las actividades sociales y culturales que constituyen prácticas de lectura y escritura conforme a los contextos que norman y valorizan las interpretaciones de los contenidos, los consumos y los productos. De igual manera, establecen y privilegian modalidades de lectura, determinan la relación entre la producción y el consumo conforme a estratificaciones sociales; y asimismo está el uso de los objetos y espacios en donde también se juegan las transgresiones, no sólo del lector, sino también de las instituciones creadas para normar usos y prácticas de lectura y escritura, de acuerdo con las orientaciones socioculturales establecidas en cada época y lugar. Pero también es importante recordar que toda tecnología crea necesidades en un marco social, cultural y económico que las favorece e incluso las torna imperativas.

El acto de leer en los textos impresos es conducido conforme a sus normas de organización, trayectorias, ritmos y espacios de lectura marcados por su linealidad dentro de los marcos de la página, en donde los códigos son fijos y, por tanto, inalterables; así, el lector sólo puede escribir notas o dibujar al margen, allí deja las huellas de su lectura y la trasgresión la ejerce en su mente. Además, el libro en sí mismo es un espacio de lectura, el texto está en ese lugar y no en otro, desde luego el lector puede llevarlo consigo a cualquier lado, sin embargo, sería complicado llevar varios. En cambio el texto digital tiene variantes para el acto de leer, ya que debe adecuarse a estructuras textuales diferentes, la lineal y la secuencial, la interactiva y la estructura fija, lo escrito y lo audiovisual, lo estable y lo mutable. El acto de leer, además de estar involucrado en las acciones de desciframiento, comprensión, construcción de sentidos y significados, en el medio electrónico añade la manipulación de los contenidos. En efecto, en el contexto del espacio virtual el lector crea, altera el texto, lo cambia al tener la facilidad de abrir su estructura e introducir sus propias producciones; en otras palabras, el lector realiza actividades de edición, por ello se afirma que se convierte en autor. Por otra parte, el acto de leer en el medio electrónico produce las textualidaes, podríamos decir que para el lector esto representa mayor complejidad, en tanto que debe producir el texto y controlar sus límites, dado que en los textos en donde se introducen ligas o ventanas que remiten a otros textos, imágenes 
o sonidos, se pueden convertir en textos interminables, porque mediante la interactividad es factible transitar por numerosas páginas.

Por otro lado en la pantalla el ojo percibe sólo fragmentos, por lo que algunas de las operaciones cerebrales difieren entre la página de papel y la pantalla. En relación con estas modalidades del acto de leer, Roger Chartier aclara que:

Los fragmentos de textos que aparecen en la pantalla no son páginas, sino composiciones singulares y efímeras. Y, contrariamente a sus predecesores, rollos o códices, el libro electrónico no se diferencia de las otras producciones de la escritura por la evidencia de su forma material. La discontinuidad existe aún en las aparentes continuidades. La lectura frente a la pantalla es una lectura discontinua, segmentada, atada al fragmento más que a la totalidad. ${ }^{21}$

Las variaciones en el tamaño del fragmento tienen implicaciones en la percepción, en los modos de asociar que toda lectura conlleva, ya que las relaciones mentales con otros textos, informaciones, experiencias, sonidos, imágenes que generaba el lector en su mente, esa metatextualidad las construye en el entorno digital y da lugar a una forma diferente de realizar la actividad a la que Patrick Bazin denomina metalectura. ${ }^{22}$ En efecto, el lector busca y elige de la variada oferta en la red; identifica, selecciona e interrelaciona productos propios y de otros dueños, por lo que las características mentales del acto de leer se llevan a cabo de manera concreta en la realidad virtual.

Por otro lado en los medios educativos nacionales poco se han difundido y aprovechado las posibilidades de la lectura social, que si bien no es una novedad se ha favorecido y potenciado en el medio virtual por las aplicaciones, tanto en los artefactos como en los formatos hipertextuales, con las que se complementan los libros y otras publicaciones electrónicos, que convierten los textos en multimedia. Por otro lado, los espacios de socialización que se ofrecen en Internet favorecen, como señala el catedrático de Filología Románica de la Universidad Complutense de Madrid, Dr. José Manuel Lucía Mejías, "una lectura mucho más colectiva." 23 Ciertamente, los textos electrónicos, además de facilitar la interactividad con los contenidos, de igual manera favorecen la comunicación entre lectores, autores, profesores, editores, es decir, las barreras de comunicación tienden a diluirse y el texto se convier-

21 Roger Chartier (2008), Escuchar a los muertos con los ojos, España: Katz. p. 12.

22 Patrick Bazin, (2007), "Hacia una metalectura”, en El futuro del libro ¿Esto matará esto?/ comp. Geoffrey Nunberg.

23 Cfr. Público es. En www.publico.es/culturas/.../el-ebook-recupera-la-lectura-colectiva (consultado 20 de noviembre 2011). 
te en un espacio de trabajo, aprendizaje y, también, lúdico. Sin embargo en relación con la comprensión lectora y la concentración en la lectura electrónica, los expertos todavía mantienen sus dudas y consideran que cuando hay música y otros enlaces, como chat o skype, el lector se distrae. Sin embargo, si lo vemos desde otro punto de vista, los que leen en el medio digital tienen mayor destreza para relacionar la información.

Esta práctica de lectura crecerá en la media que lo libros electrónicos y las aplicaciones para la lectura multipliquen su oferta y accesibilidad, lo que contribuirá al proceso de enseñanza aprendizaje y también fortalecerá las habilidades de lectura y escritura. Por ejemplo el libro blando o expanded book, como lo denomina Antonio de las Heras, en formato hipertextual se despliega en multitud de bucles y convierte al lector en un navegante que surca a través de caminos variados. ${ }^{24} \mathrm{El}$ cual, señala el autor, "puede crear una relación más fuerte con los lectores". Estos libros en el espacio de Internet se instalan en una red tecnológica y social donde los límites se expanden de manera elástica; se establece así una actividad de los lectores con el texto y entre los lectores, y puede entonces realizarse la práctica de lectura social, el intercambio de opiniones con otros alumnos, no sólo de su ámbito de clase sino también con estudiantes de otros países e incluso con los autores y editores, de manera que se posibilitan relecturas diferentes y reescrituras del texto; las contribuciones, sean escritos icónicas o sonoras, se incorporan al texto original a manera de intertextos en donde se agrega la autoría. Y el texto se va ampliando, incluso el profesor puede utilizarlo con otros grupos.

Esta modalidad de lectura plantea la necesidad de desarrollar otras habilidades más complejas o distintas a las que requiere la lectura de los medios impresos. Incluso algunos lectores afirman que la lectura de textos electrónicos requieren de un mayor esfuerzo de concentración, en especial los lectores jóvenes que de manera simultánea al acto de leer realizan otras actividades: chat, correos, o que tienen diferentes ventanas abiertas en la pantalla para interactuar con contenidos variados: imágenes, música, textos. En cuanto a los espacios, los contenidos, que pueden ser numerosos, pueden leerse en diferentes artefactos electrónicos, o acceder y consultarlos en distintos lugares o imprimirlos.

En cuanto a los cambios en el cuerpo de los lectores, las características de los artefactos o soportes y la propia pantalla exigen determinados gestos, aun cuando es una función del ojo que requiere de ciertas adaptaciones de ese órgano, y del manejo manual, en especial con las pantallas táctiles. Los

24 Heras, Antonio de las,"Hipertexto. El texto plegado", en El Urogallo", 121, 1996, pp. 30-33, citado por Laura Borras Castanyer (editora), Textualidades electrónicas, Madrid: Editorial, UOC, 1998, p.92. 
artefactos especiales para leer, o las lap tops, ofrecen más comodidades que las computadoras de escritorio que es el medio todavía más usado. Es el caso de los estudiantes del bachillerato de la UNAM, de los cuales pocos poseen una lap top, y menos aún una tableta electrónica. En el diagnóstico que se realiza cada año sobre la población que ingresa al bachillerato de esta casa de estudios, se encontró que 58.7\% tiene computadora personal fija y el 79\% teléfono celular. ${ }^{25}$

La lectura en pantalla seguramente tiene diferentes valoraciones para cada sujeto. Al igual que sucede con los textos impresos, su materialidad tiene efectos en el aspecto simbólico, al igual que en su contenido, y también por el género, el tamaño del contenido, la duración de la lectura, por el tema, por el contexto o por la finalidad, lo cual varía de un lector a otro. El "libro de papel" entre las nuevas generaciones es un objeto de lectura diferente al artefacto electrónico, como puede apreciarse en estos testimonios que coinciden con otros de la misma comunidad de jóvenes:

\section{Frida 17 años}

No, las computadoras, las pantallas, si acaso para jugar, pero no para leer; no es lo mismo ver la hoja, pasarla, a ver la pantalla

\section{Erick 16 años}

Porque un libro estando viendo en la pantalla no lo puedes palpar ni sentir con tus propias manos

\section{Arely de 17 años}

En original, pues según yo pues te imaginas más las cosas y si no lo entiendes lo vuelves a leer y en cambio si lo pones... lo tienes, lo metes en la pantalla como que se te pierde la vista luego de que volteas a algún lado y "ay, dónde me quedé" y entonces pues, no sé, creo que sería mejor por el original.

\section{Pablo 18 años}

El Internet, juy no! Para leer no me agrada nada, no me gusta leer nada en Internet.

Solamente por necesidad, pues cuando lo tengo que hacer pues ni modo, pero por gusto, que yo busque algo, un artículo, algo que me interese, recurro más a los libros, algo que yo tenga materialmente, no me gusta leer en la computadora.

\section{Mauricio 18 años}

Yo prefiero estar aislado, es más, cuando leía mejor era cuando iba en el camión, cuando no iba haciendo nada iba leyendo, aparte es cansado leer en la computadora tanto texto como que los ojos te empiezan a quemar y no me gusta prefiero tener los libros.

25 Universidad Nacional Autónoma de México (2011), Perfil de aspirantes y asignados a bachillerato y licenciatura de la UNAM 2010-2011, Cuadernos de Planeación Universitaria, año 2011. 
Respecto a estas opiniones, de alguna manera concuerdan con la afirmación de Román Gubern, quien considera que el libro impreso es el producto de una tecnología compleja, pero que se disfruta de un modo técnico muy simple, al contrario de la lectura de textos procedentes de la familia electrónico-digital. ${ }^{26}$ Es comprensible que para muchos de estos estudiantes la computadora fija sea un artefacto incómodo para la lectura prolongada por un lado, y, por el otro, los libros electrónicos en español con aplicaciones más versátiles son escasos o no cubren las necesidades e intereses de los jóvenes, de tal manera que para ellos la facilidad de lectura y la relación sensual que les produce el objeto "libro de papel", todavía está anclada a sus representaciones relacionadas con el acto de leer. Además los afectos que establecieron con el libro desde pequeños, se ancla de manera simbólica en las representaciones de la lectura, e intervienen en el sentido y significado de sus lecturas. En cambio, en el artefacto electrónico la relación placentera puede encontrarse en la manipulación y simulación, en donde el ser humano, como propone Slavoj Žižek, puede crear un "mundo" (virtual) paralelo, pues los lectores elaboran un montaje con fragmentos de texto, imágenes, música y otros sonidos, videoclips, etc., para darle cauce a sus deseos, ${ }^{27} \mathrm{y}$ lograr experiencias placenteras, Así, en el sentido y significado que cada lector formula de los contenidos en el medio digital, el artefacto está siempre presente y aunque se han simplificado sus aplicaciones de cualquier manera le demanda a los lectores mayor número de operaciones manuales y mentales para poder interactuar con el texto/hipertexto que lo invita a re-crearlo, a diferencia del medio impreso, en el cual las operaciones son intelectuales ante un texto fijo dado en el continente de una página que no debe controlar, sino que al contrario, le representa un marco y una estructura que guía sus lecturas.

En cuanto a las prácticas, al ser éstas culturales y sociales, como ya lo señalábamos, implican los valores, las normas, los usos y los contextos. En este sentido, Eloy Martos señala que:

Las prácticas de lectura surgen siempre de interacciones sociales y culturales, hasta el punto de que los antiguos antagonismos entre lo individual y lo colectivo, lo espiritual y lo material, lo tangible y lo intangible, se pueden conciliar o superar fácilmente, porque un ambiente es siempre algo físico y mental a la vez. Por ejemplo, lo que hace de un aula una "sala letrada" no es un solo factor, sino una conjunción de factores personales, materiales y ambientales. ${ }^{28}$

26 Román Gubern (2010), Metamorfosis de la lectura, España: Anagrama, p. 87.

27 Žižek Slavoj (2009), El acoso de las fantasías, $3^{a}$ reimp., México: Siglo XXI, p. 148.

28 Eloy Martos Núñez, ¿Espacios de lectura o "espacios letrados”?, en Congreso Internacional Virtual de Educación Lectora, p. 4. http://www.universidadeslectoras.org/, [02/03/2011] . 
En el contexto del ciberespacio, la incorporación de la web 2.0 constituye una evolución para facilitarle a los usuarios su participación, presencia y comunicación en espacios sociales, y también el acceso e intercambio de información en forma de texto, imagen o sonido. Precisamente una parte importante de las actividades en ese espacio se desarrolla por medio de la escritura y la lectura; entre las nuevas prácticas cotidianas de esas dos actividades se encuentran el correo electrónico, la lectura de diarios electrónicos, los comunicados del entorno laboral o escolar, los mensajes de texto de variadas fuentes y modalidades a las que se accede también vía teléfono móvil.

Entre las prácticas derivadas de lo que ahora se denomina social reading, lectura social, consideramos pertinente incluir las que se producen en el chat y en las redes sociales, porque son modalidades que se asemejan a una conversación escrita y están más próximas a la modalidad del diálogo, ya sea entre dos participantes o más. En cuanto a la lectura social es un tipo de club de lectura virtual que ha surgido en el círculo de los libros electrónicos y sitios en donde se encuentran redes organizadas por intereses. ${ }^{29}$ Se trata de una práctica que si bien no es nueva, dado que ha formado parte de monasterios, plazas públicas, bibliotecas, iglesias, salones de tertulia, clubes de lectura, entre otros, sin embargo aparece como una novedad en el ámbito digital. Los editores de libros, tanto los académicos como los de literatura, agregan aplicaciones para crear blogs, wikis y redes sociales que pueden utilizarse en diferentes artefactos, computadoras, tabletas y en los teléfonos avanzados, con ello el texto se transforma en un espacio en donde se crean las sociabilidades con participantes locales y de diferentes latitudes. Es decir, el texto, ahora es convertido en el lugar de reunión para intercambiar opiniones, ocurrencias, conocimientos, experiencias; incluso en ese espacio se hacen visibles las acciones del lector sobre el texto en sus anotaciones. Esto ahora se ha empezado a utilizar en el ámbito educativo, no sólo de los sistemas en línea, también en las modalidades presenciales. Esta forma de leer permite desvelar el espacio privado de lo que la lectura suscita en la mente del lector, es decir, nos deja entrar en una parte de su intimidad, a diferencia de lo que proponía Margarite Duras: "se lee en la oscuridad... La lectura es un signo de

29 Por ejemplo en México el sitio Libros y Lectores, fue creado en alianza entre la Secretaría de Cultura Estatal de Colima y el Consejo Nacional para la Cultura y las Artes (Conaculta), para facilitarle a los usuarios el hecho de interactuar y abordar temas relacionados con todo tipo de libros, desde lecturas infantiles, hasta novelas y biografías. En Estados Unidos Goodreads es uno de los sitios más grandes visitado por 7 millones una vez al mes y 100 mil nuevos usuarios al mes. Otros sitos son Readfeeder, Shelfari, Booklamp, Book Glutton, entre otros. En español se encuentra el Liibook, red social para aficionados a la lectura, Lecturalia, Red social de literatura, comunidad de lectores y comentarios de libros. 
la oscuridad de la noche. Aun si leemos a pleno sol, afuera, la noche se agolpa en derredor del libro".30

\section{LOS USOS DE LOS ARTEFACTOS ELECTRÓNICOS}

EN LAS ACTIVIDADES DE LECTURA E INFORMATIVAS

Precisamente los lectores desarrollan en los contenidos electrónicos nuevas prácticas de lectura, ya no sólo formativas e informativas sino también lúdicas. Es el caso de los libros infantiles que ofrecen la activación de una voz que lee, o transforma a los personajes, cambia su aspecto o incluye música; así, el libro y otros sitios electrónicos se convierten en espacios multimedios para jugar y para aprender.

En los siguientes testimonios de algunos jóvenes podemos apreciar diversos usos del espacio electrónico en donde están involucradas las prácticas de lectura propias de la cultura digital, si bien todavía no se aproximan a las descritas con anterioridad porque el acceso y uso de los libros electrónicos se encuentra en una etapa incipiente:

\section{Mauricio 18 años}

Siempre el FB, [Facebook] el Messenger, también veo videos, más que nada "bajo" música y leo las letras, como me gusta mucho la música en inglés me pongo a leer las letras, por ejemplo, hay grupos que sacan un disco con toda una historia y cada canción te cuenta y es igual, hay que ir armando las piezas y es como una novela, hay que ir leyendo la canción y pues ya te lo vas imaginando y con la música te ayuda a expresar cómo es el personaje si es tranquilo o si es agresivo o feo o te lo imaginas muy alto, o algo así, bueno a mí me ayuda.

\section{Balaam 17 años}

Me gusta mucho la fotografía, las fotos que tomo las edito, hago videos, me gusta mucho investigar datos curiosos, de hecho leo Algarabía, tenemos casi la colección, una cosa que no está completa la reviso y demás, sí me gusta cómo saber cosas......a veces me quedo en Wikipedia, pero sí procuro investigar.. He bajado por ejemplo los últimos dos de Harry Potter, así los leí, los de Narnia, y así, Asamblea de mujeres lo "bajé" porque no lo encontraba y creo que nada más.... no me gusta leer mucho en la computadora, te cansa la vista y demás, de hecho los "bajo" y los imprimo y así los leo. 
Arely de 17 años

Para sacarle las reseñas a algún libro y ver de qué se trata y si me llama la atención para pedírselo a mis papás para comprarlos, novelas serias de moda por ejemplo Harry Potter y la saga de Crespúsculo. Pero está bien que los libros también estén en Internet, porque muchas personas no tienen tiempo para una biblioteca.

Fácil de adquirir un libro y que todos... la mayoría tendríamos acceso a ella, y la mayoría busca por internet.

\section{Beatriz 17 años}

El Internet, pues es una herramienta muy útil, para lo académico me sirve mucho para las tareas, porque se encuentran lecturas de todo tipo y pues sí es muy fácil, pero sí hay que tener cuidado con la información, porque luego no viene muy bien. Pero sí está bien, porque uno encuentra textos de muchos lados en varios idiomas y que muchas veces no son accesibles, así si uno va a buscarlos en un libro.

\section{Axel 18 años}

El procesador de texto lo uso mucho.

Leí El Hombre Araña, y "bajo" de Internet novelas gráficas, eso leo, Civil War y una de Batman que se llama el Hombre que Sonríe que es del Guasón, bueno, es de cuando el Guasón se muere, pero de repente leo novelas gráficas

Por lo que se aprecia en las declaraciones de estos los jóvenes lectores están comenzando a usar los artefactos digitales para la lectura de libros de literatura, pero todavía la lectura digital de libros, periódicos y revistas no es frecuente, como sí lo es la que se utiliza para comunicarse y buscar información.

\section{IDENTIDADES DE LOS LECTORES EN LA CULTURA DIGITAL}

Los jóvenes entre 15 y 24 años de edad comparten el nacimiento y el progreso de la cultura digital, y también el proyecto de sociedad global de la información y la tecnología electrónica y de la comunicación, que configuran el contexto en el cual surgen nuevas identidades. Dichos jóvenes son considerados como "nativos digitales" o "webactores", y se distinguen por valorizar y preferir la cultura digital sobre otras modalidades culturales, y además porque desarrollan habilidades altamente perfeccionadas para interactuar con los medios electrónicos. Como los describen Palfrey y Gasser: los congregan sus prácticas, el tiempo destinado al uso de tecnologías digitales, su tendencia a interactuar en el medio electrónico, de manera simultánea con diferentes actividades (multitaskers) la tendencia a expresarse y relacionarse 
por medio de las tecnologías digitales y los patrones de uso de tecnologías para acceder a la información y producir nuevo conocimiento y creaciones artísticas. ${ }^{31}$ La identidad de los "webactores" tiende a popularizarse, y para diferenciarlos del consumidor considerado "pasivo" se alude a una identidad de usuario que a la vez es creador y productor, con capacidad de modificar y darle forma a la Web de hoy. Al respecto, F. Pisani y D. Piotet señalan que el $60 \%$ de los datos son colocados por estos actores convertidos en creadores, lectores/escritores, oyentes/locutores, espectadores/productores. Además, organizan y modifican la información, y tienden a colaborar en grupos y redes sociales. Para estas comunidades el sentido no está colocado en acumular y conservar información, sino en generarla y compartirla.

Las posibilidades hasta ahora logradas han sido favorecidas en parte porque la tecnología es cada vez más discreta, es decir, menos complicada en favor de la libertad para la creación, y la expansión y creatividad de la inteligencia colectiva, que reditúa en el aprovechamiento de la población que los utiliza a través de Internet; y también porque los jóvenes perfeccionan sus habilidades para crear y manipular los medios electrónicos. Es importante destacar que innovaciones importantes del entorno cibernético son aportaciones de jóvenes que han logrado revolucionar los medios digitales. Por lo general, las nuevas generaciones son más proclives a aceptar las novedades, pero también entre las comunidades de mayor edad se encuentran entusiastas usuarios de las tecnologías, en la medida en que éstas echan raíces en gran parte de la vida cotidiana y se extienden a diferentes sectores de la sociedad.

La identidad de los jóvenes como nativos digitales o webactores se ha generalizado, aun cuando no todos los jóvenes pueden considerarse de manera plena dentro de tales caracterizaciones. La concepción sobre los jóvenes se fun$\mathrm{da}$, en buena medida, en las estadísticas respecto de su uso, que reflejan a los jóvenes como el público que más usa y frecuenta el medio digital, además los jóvenes son actores activos de las redes sociales; sin embargo, no necesariamente corresponden plenamente a las identidades antes señaladas. En los fragmentos de las narraciones que incluimos a continuación, los jóvenes no se identifican totalmente con esas identidades, incluso llegan a preocuparse porque las generaciones más jóvenes se olviden de los libros impresos, como observamos en estas reflexiones: 


\section{Christian 17 años}

Yo siento que Internet es así ahorita como... es como un arma de dos filos, porque a las generaciones que vienen le están dejando todo en Internet, y ¿qué pasa con los libros? Y eso está mal porque nos están enseñando a depender del Internet y no a hacer realmente una investigación en los libros; yo lo veo con mi hermana, le dicen "todo de Internet, todo de Internet". Entonces, sí hay artículos y hay cosas muy buenas en Internet, pero siento que también deberían de fomentar a que no sólo es Internet, que también debe haber otras fuentes.

\section{Paloma 18 años}

Bueno siempre he dicho, internet es un arma de dos filos, es un arma que te puede Ilevar a conocer de muchas cosas, o que te puede llevar a ignorar muchas cosas, dependiendo de cómo lo tomes, por ejemplo, lo que me decía hace rato del correo... ah no me lo decían allá pues, que si considero el correo como una forma de lectura, no, porque no te deja más allá de algo que tú ya conoces; escasos son los correos que te mandan que te informan acerca de algo, pero sí he llegado a buscar, bueno... fue un poquito más que lecturas, inquietudes que tengo, o qué significa tal cosa o el porqué de equis cosa, y leo, igual, he leído textos científicos, así que como ya dije los traigo de parte de mi papá, esa curiosidad y entonces sí ha saciado muchas veces mi sed como por saber por qué, nada más.

En México, según el Estudio de Consumo de Medios Digitales de IAB México, la Internet es parte de la vida de las personas, especialmente los adolescentes y jóvenes, que cada vez son más "multitaskers" y que de manera simultánea, realizan varias actividades: leen, escriben, navegan, revisan su correo electrónico, escuchan y "descargan" música y video, editan blogs, y además socializan, por ello se les considera multitaskers, como lo podemos constar en esta narración:

\section{Mauricio 18 años:}

Es muy distinto porque de repente como ahorita está todo eso de la onda del Messenger, del Facebook y todo eso, cuando tienes la computadora la usas para eso y de repente estás haciendo la tarea 0 estas platicando y te distrae mucho y leer un libro, allí te da la tentación de ver quien está conectado 0 a ver qué ha pasado y como que no es muy cómodo

En la misma encuesta antes citada, se identificó que el 50\% de los jóvenes mexicanos usuarios de la Internet la consideran indispensable en su vida y 51\% la "aman". El 44\% disfrutan usarla y el 57\% dice que es el medio que más usan. El $44 \%$ indica que los mantiene actualizados y es considerada por el 31\% como el medio de comunicación más accesible. En cuanto a los usos de Internet, la joven audiencia mexicana es ávida consumidora de contenido 
de entretenimiento, particularmente música y videos. ${ }^{32}$ El Instituto Nacional de Geografía y Estadística (INEGI), encontró que entre el 32 al 36 \% de los usos de Internet se concentran en cuatro actividades: obtener cualquier tipo de información general, correo electrónico, fines educativos y chat; pero también los blogs que empiezan a popularizarse. Dichas actividades corresponden con las declaraciones de los jóvenes entrevistados, en donde la lectura y la escritura, como ya lo considerábamos, están involucradas, pero todavía no se han legitimado entre las prácticas sociales de lectura; incluso utilizan otros términos para referirse a ella: visitar, navegar, mirar, consultar, entre otros.

Sin embargo una de las ventajas que los jóvenes privilegian es la rapidez para obtener la información que necesitan para sus tareas escolares. Así lo hacen constar los siguientes testimonios:

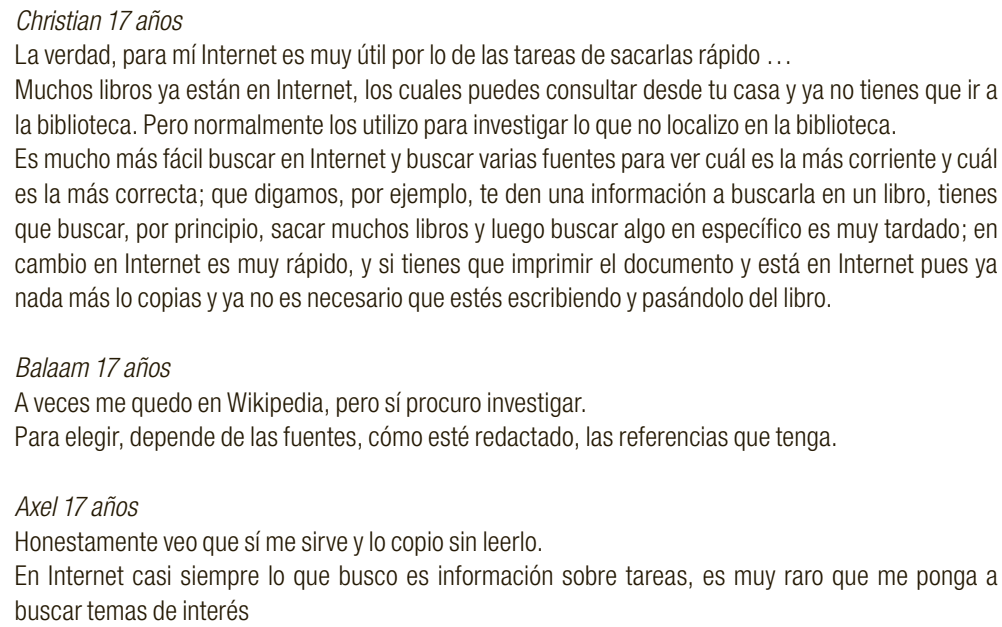

A la vez, tiende a elevarse el número de horas que las personas, no sólo jóvenes, pasan leyendo -en especial textos cortos-, hablando o viendo imágenes, escuchando música o socializando por Internet, no sólo por la redes sociales, sino que también se han popularizado las video llamadas. Por su parte, las redes sociales electrónicas, crecen de manera acelerada, Facebook

32 ComScore, Inc., Proprietary and Confidential, http://www.comscore.com/esl/layout/set/ popup/request/Presentations/2010/State of the Internet with a Focus on Mexico and Latin America Spanish PDF, [consultada: 20/febrero/2011]. 
y Twitter registraron crecimientos sobresalientes en 2010, ya que más de $85 \%$ de los internautas cuentan con al menos una red social. En cuanto a los internautas mexicanos las utilizan más que el año anterior, siendo Hi5 y YouTube los que destacan como lugares preferidos para compartir fotos y videos.

\section{EN CONCLUSIÓN}

La representación social que se ha venido construyendo en torno a la identidad de los jóvenes como hábiles internautas o webactores, se sobredimensiona y generaliza bajo suposiciones respecto de su dominio y habilidades muy desarrolladas para el uso de la tecnología, la selección y uso de los contenidos. Esta representación coloca a los adultos en la categoría de "inmigrantes digitales" y generaciones "predigitales", dadas las limitaciones en cuanto a las destrezas, y la dificultad para interactuar con la lógica de los artefactos electrónicos; por lo mismo se propicia la autoexclusión por parte de los adultos en cuanto a sus posibilidades de contribuir a la formación y orientación de las nuevas generaciones. Sin embargo en los relatos de jóvenes se hace evidente que existe la necesidad de contar con programas orientados a la formación de lectores plenos; es decir, capacitados para manejar diferentes códigos y géneros, y también para desarrollar habilidades, realizar diferentes tipos de lectura: literal, analítica, crítica y también habilidades informativas, indispensables para conocer, seleccionar y discriminar las fuentes conforme a las distintas necesidades y utilizar la información. En la actualidad la función de la bibliotecología en la formación de lectores afronta una mayor complejidad, y a la vez esa función adquiere una importancia trascendental, en especial en las nuevas generaciones en las que en su infancia el uso de las TIC era un tanto limitado, pero también entre los adultos, tal es el caso de los docentes, los padres de familia y los propios bibliotecólogos, además de los promotores de lectura.

Por ello, en al ámbito sociocultural en que la bibliotecología está comprometida, al igual que otras disciplinas involucradas en el estudio de lo humano, debemos estar atentos a la reflexión de Michael de Certeau, basada en la afirmación de Alvin Toffler, quien anunciaba el nacimiento de una "nueva especie" humana, engendrada por el consumo artístico de masas. Esta especie en formación transhumante y voraz entre las praderas de los medios, tendría como rasgo distintivo su "automovilidad". Certeau agrega: "Volvería al nomadismo de antaño, más para cazar en lo sucesivo en estepas y bosques artificiales". Considera que no sólo en el consumo de arte, sino también en la lectura, las comunidades podrían quedar atrapadas de la manera que el autor describe: 
Fijación de consumidores y circulación de los medios. A las muchedumbres les quedaría solamente la libertad de rumiar la ración de simulacros que el sistema distribuye a cada uno. ${ }^{33}$

Los seres humanos aprenderemos a vivir en soledad en un espacio que incluye a la vez el espacio electrónico o virtual en los cuales el lector puede acceder, como ya lo mencionamos, a una diversidad de recursos, o "viajar" a través de los hipertextos a lugares remotos moviéndose de un sitio a otro, visitando museos, mirando películas, escuchando música e incluso asistiendo a conciertos.

El acto de la lectura electrónica puede ser realizado de manera superficial o profunda. Las experiencias de lectura podrán ser tan significativas como las que suceden con los libros de papel. O algo similar a lo que ocurre con la TV o la radio y también algunas editoras que ofrecen contenidos seleccionados, y censurados bajo criterios e intereses ideológicos o económicos con los cuales dominan el universo de los expectores y lectores, quienes quedan a merced de sus productos. Precisamente es ese futuro en contra, y contra quienes pretenden controlarlo todo (ya se ve en el horizonte la configuración de restricciones con apariencia de protección de derechos de autor, a la Ley Stop Online Piracy Act, SOPA), que revive el temor y el deseo de que las personas sean moldeadas por lo escrito (sea éste verbal o icónico), y se vuelvan sujetos impresos por medio del texto y a semejanza del texto que se les impone. ${ }^{34}$ esto nos lleva a la antigua idea de que los lectores son sujetos pasivos, pero para la bibliotecología los lectores no son más activos debido a las fallas de algunos sistemas educativos que han privilegiado la lectura memorística y poco fecunda, y también por una desigual distribución de ofertas culturales. Pero, el problema no está de todo en los contenidos, como ahora se piensa de los productos electrónicos, sino en la formación de los lectores, la cual debe fortalecer el desarrollo de las capacidades que se requieren para progresar hacia una lectura crítica. Así, en la medida en que nos formemos como lectores plenos, se obtendrán efectos positivos en los productos que se consumen y generen. Actualmente tanto en los medios impresos como en los electrónicos, la lectura profunda y crítica implica proceso de mayor complejidad y detenimiento para comprender, asimilar y discriminar la calidad, sin embargo, en el medio digital el lector debe "navegar" contra corriente par ano sucumbir a la inmensa oferta, a la inmediatez y a la facilidad que le brinda el ciberespacio para localizar y acceder a la información. Finalmente la

33 Michel de Certeau. (1996) Leer: una cacería furtiva. En Invención de lo cotidiano. México: 
lectura puede contribuir a engrandecer el espectáculo más maravilloso, como lo consideraba Abdala el Sarraceno quien nada veía más espléndido que el hombre. ${ }^{35}$

Por otro lado, es necesario concebir la formación de lectores sobre las bases de una noción de lectura más compleja, porque la cultura digital nos coloca frente a la necesidad de incorporar habilidades y prácticas de lectura y creación de contenidos en textualidades poliédricas. En este sentido, Vásquez Rocca considera que

el soporte digital fractura la linealidad narrativa propia de los soportes analógicos, ya que [le] confiere al texto una arquitectura poliédrica, lo abre y lo expande, lo fragmenta y lo convierte, gracias a las redes, en ubicuo y participativo. ${ }^{36}$

De esta manera el lector crea y controla la textualidad en su acto de lectura, por lo que los lectores se encuentran ante un proceso más complejo. Ante ello los bibliotecólogos debemos revisar el concepto de lector, antes que conformarnos con las identidades lectoras contenidas en las denominaciones "nativo digital" y "webactor", que representan a las nuevas generaciones de "multialfabetas", como propone la UNESCO, pues los lectores además de desarrollar habilidades para interactuar con diferentes lenguajes, deben tener una capacidad crítica y un uso adecuado de la información para diferentes necesidades y es por eso que se busca que las prácticas lectoras sean congruentes con esas cualidades.

Por lo anterior es importante renovar los fundamentos bibliotecológicos sobre la lectura y los lectores, e ir más allá de las concepciones reduccionistas o utilitarias de la lectura, en tanto que es una actividad involucrada en la formación subjetiva, y por tal razón tendríamos, como señala Jorge Larrosa, que cancelar esa frontera entre lo que sabemos y lo que somos, entre lo que pasa (y que podemos conocer) y lo que nos pasa (como algo a lo que debemos atribuir un sentido en relación a nosotros mismos). Para lograrlo la bibliotecología tendría que buscar caminos que incorporen la experiencia como parte fundamental de la formación de lectores pensada como construcción de sí misma a fin de recuperar de paso, lo que Giorgio Agamben señala: "La constitución del sujeto a través del lenguaje en el cual sus experiencias adquieren forma y significancia en la palabra, y el relato, ya que actualmente la

35 Giovani Pico della Mirandola Discurso sobre la dignidad del hombre. En revista Digital Universitaria 1 de noviembre 200, Volumen 11 Número 11. http://www.revista.unam.mx/vol.11/ num11/art102/art102.pdf

36 Adolfo Vásquez Rocca. (2004), "El Hipertexto y las nuevas retóricas de la postmodernidad; textualidad, redes y discurso excéntrico". Revista philoshophica, núm. 27, <http://www.philosophica.ucv.cl/abs27Vasquez.pdf>, [consultada: 20/agosto/2011]. 
humanidad ha perdido la experiencia que antes constituía la materia prima que cada generación transmitía a la siguiente. ${ }^{37}$

En el escenario actual, los bibliotecología tendrá que formular propuestas orientadas a fortalecer, con mayor ímpetu, la función de "mantener viva la biblioteca como espacia de formación ${ }^{38}$ de lectores y de experiencias de lectura, además, preservar abierto ese espacio en el que cada uno pueda encontrar su propia inquietud. Y con ello lograr que la lectura pueda contribuir a "engrandecer el espectáculo más maravilloso, como lo consideraba Abdala el Sarraceno, quien nada veía más espléndido que el hombre". ${ }^{39}$

\section{Bibliografía}

Bazin, Patrick (2007), Hacia una metalectura, en El futuro del libro ¿Esto matará esto?, comp. Geoffrey Nunberg

Carrière, Jean-Claude y Umberto Eco (2010), Nadie acabará con los libros, México: Lumen.

Certeau, Michel de (1996), Invención de lo cotidiano, México: Universidad Iberoamericana, Departamento de Historia, T. I Artes de hacer.

Chartier, Roger (2008), Escuchar a los muertos con los ojos, España: Katz.

Doueihu, Milad (2010), La gran conversión digital, Buenos Aires: Fondo de Cultura Económica.

Foucault, Michel (1991), Las palabras y las cosas. Una arqueología de las ciencias bumanas, /trad. E.C. Frost, $21^{a}$ ed., México: Siglo XXI.

Galindo Cáceres, Jesús (2006), Cibercultura. Un mundo emergente y una nueva mirada. México: Consejo Nacional para la Cultura y las Artes.

Gubern, Román (2010), Metamorfosis de la lectura, España: Anagrama.

Heras, Antonio de las."Hipertexto, El texto plegado En: El Urogallo", 121, 1996, pp. 30-33, en: Laura Borras Castanyer (editora), Textualidades electrónicas, Madrid: Editorial, UOC, 1998, p.92.

37 Giorgio Agamben (2007) Infancia e historia. Destrucción de la experiencia y origen de la bistoria. Buenos Aires, Adriana Hidalgo Ed. p. 64, 4

38 Esta idea de la adaptación de la propuesta de Larrosa, quien señala que "la crisis de la formación humanística de la formación, por ello propone que la "función del profesor, es la de mantener viva la biblioteca como espacio privilegiado de formación. Jorge Larrosa (2003) La experiencia de la lectura: estudios sobre literatura y formación.

Nueva edición revisada y aumentada. México, Fondo de Cultura Económica, p. 31, 45

39 Giovanni Pico Della Mirandola. Discurso sobre la dignidad del hombre. En Revista Digital Universitaria. 1 de noviembre 2010. Volumen 11, Número 11. http://www.revista.unam. $\mathrm{mx} /$ vol. 11/núm. 11/ art102/aet102.pdf 
Hine, Christine, Etnografía virtual, Editorial UOC, (Nuevas Tecnologías y Sociedad).

Jodelet, Denis, "El movimiento de retorno al sujeto y el enfoque de las representaciones sociales", en Cultura y representaciones sociales. Un espacio para el diálogo transdisciplinario, vol. 3, núm. 5, < http://www.culturayrs.org.mx/revista/num5/Jodelet.pdf>, [consultado: 14/diciembre/ 2010].

Levy, Pierre (2007), México. Universidad Autónoma Metropolitana Unidad Iztapalapa.

Martos Núñez, Eloy, ¿Espacios de lectura o "espacios letrados”?, en Congreso Internacional Virtual de Educación Lectora.

Mir, Adolfo (1974), Cultura y sociedad. Las ciencias sociales, México: ANUIES.

Palfrey, John and Urs Gasser (2008), Born digital. Understanding the first generation of digital natives, New York: Basic books.

Picard, Dominique (1986), Del código al deseo; el cuerpo en la relación social. Barcelona: Paidós.

Público es, en www.publico.es/culturas/.../el-ebook-recupera-la-lectura-colectiva (consultado 20 de noviembre 2011).

Qi, Jie and Lean Buechley, Electronic popables: exploring paper-based computing through an interactive pop-up book, <http://web.mit. edu/jieqi/Public/DREU_Site/Jie_Qi_DREU.pdf> [consultada: 15/ agosto/2011].

State of the Internet with a Focus on Mexico and Latin America ComScore, Inc. Proprietary and Confidential, enhttp://www. comscore.com/esl/layout/set/popup/request/Presentations/2010/State of the Internet with a Focus on Mexico and Latin America Spanish PDF, [consultada: 20/febrero /2011].

Universidad Nacional Autónoma de México (2011), Perfil de aspirantes y asignados a bachillerato y licenciatura de la UNAM 2010-2011, Cuadernos de Planeación Universitaria año 2011, <http:www.planeacion.unam.mx/.../perfiles/aspirantes/asp2010-2011.pdf>

Vásquez Rocca, Adolfo (2004), "El Hipertexto y las nuevas retóricas de la postmodernidad; textualidad, redes y discurso excéntrico", en Revista philoshophica núm. 27, <http://www.philosophica.ucv. cl/abs27Vasquez.pdf> [consultada: 20/agosto/2011].

Winocur, Rosalía (2009), Robinson Crusoe y tiene celular, México: Siglo XXI, Universidad Autónoma Metropolitana.

Žižek, Slavoj (2009), El acoso de las fantasías. $3^{\text {a }}$ reimp., México, Siglo XXI. 
